\title{
A CONSTRUÇÃO DO PAN-AMERICANISMO NAS PÁGINAS DE AMÉRICAS
} (1949-1969)

\section{THE CONSTRUCTION OF PAN-AMERICANISM ON THE PAGES OF AMERICAS MAGAZINE (1949-1969)}

Mojana Vargas ${ }^{1}$

Resumo: Neste trabalho analisamos a revista Américas, publicação da Organização dos Estados Americanos (OEA). Lançada em 1949 e encerrada em 2012, passou por diversas reformulações em sua composição por força das mudanças conjunturais ocorridas no sistema interamericano e na própria OEA, funcionando como uma pequena janela pela qual é possível vislumbrar o desenvolvimento dos debates sobre as questões econômicas, sociais e políticas do continente, bem como os reflexos da Guerra Fria para as relações regionais.

Palavras-chave: Pan-americanismo; OEA; Guerra Fria; Representações.

Abstract: In this work we analyze Americas magazine, edited by the Organization of the American States (OAS). Published from 1949 to 2012, it has undergone several reformulations responding to changes on the conjuncture of the Interamerican system and in the OAS, functioning as a small window through which we can glimpse the development of discussions on economic, social and political issues on the continent as well as the effects of the Cold War to regional relations.

Keywords: Pan-Americanism; OAS; Cold War; Representations.

\section{Introdução}

Este trabalho tem como objetivo apresentar parte dos resultados de um estudo sobre a revista Américas, periódico publicado pela Organização dos Estados Americanos (OEA) a partir de 1949 e distribuído para os EUA e toda a América Latina. O periódico foi utilizado como fonte para a análise da construção do discurso pan-americano durante a Guerra Fria, com ênfase para sua fase inicial, entre os anos de 1949 e 1969.

Editada em três idiomas, a publicação cujo princípio era "apresentar a

1 Profa. Msc. Relações Internacionais da Universidade Federal da Paraíba. 
América aos americanos", foi um importante instrumento de propaganda para a OEA, funcionando como meio de divulgação dos feitos e conquistas da entidade e atuando no que seus editores pensavam ser o fortalecimento dos princípios e ideais subjacentes ao pan-americanismo.

A partir do recorte proposto pretende-se mostrar o surgimento e a evolução de um veículo de comunicação que é profundamente influenciado - ao mesmo tempo em que procura exercer alguma influência - sobre o panorama das relações interamericanas, enfatizando a abordagem dos problemas econômicos da região. Neste artigo analisaremos a publicação desde o seu lançamento até a exclusão do governo de Cuba do âmbito do sistema interamericano em 1962, para ajudar a revelar as tensões que resultaram nas diversas idas e vindas da revista e da própria Organização. Ao congregar as vinte e uma das repúblicas que compunham o continente americano no momento de sua fundação em 1948, a OEA refletia o jogo de poder e a assimetria existente entre o principal ator regional - os EUA - e seus vizinhos, cujos interesses e necessidades nem sempre coincidiam com as disposições da superpotência do norte.

Trata-se também de uma pesquisa feita a partir de uma fonte primária até então não estudada e sobre a qual o conhecimento ainda é bastante limitado. Partindo-se do tratamento documental das fontes selecionadas, também se utilizou bibliografia auxiliar para o esclarecimento de questões que as fontes por si sós não puderam responder, posto que estas nem sempre são produzidas com o objetivo de servir de base para os questionamentos propostos pelos pesquisadores. Nas palavras de Le Goff (2004, p.54):

\footnotetext{
O documento não é inocente, não decorre apenas da escolha do historiador, ele próprio parcialmente determinado por sua época e seu meio; o documento é produzido consciente ou inconscientemente pelas sociedades do passado, tanto para impor uma imagem desse passado quanto para dizer a verdade. (grifo do autor)
}

Consideramos que Américas foi utilizada não apenas como um veículo de informação, mas sobretudo como um meio para se construir representações (Chartier, 1988) da e para a América Latina que apoiaram a construção das relações 
políticas e econômicas entre os países da região e os EUA. Tais representações ajudaram a construir e a modificar imagens e crenças compartilhadas entre os atores daquele ambiente internacional específico constituindo-se em percepções da realidade, frequentemente contrastadas com o fluxo de informações (Jervis, 1976).

Américas, como material jornalístico, não constitui uma reprodução objetiva da realidade, mas sim uma reconstrução da mesma, mediada pelo olhar do redator que recorta e seleciona os elementos da realidade para produzir a informação que quer fazer chegar ao seu leitor (Genro Filho, 1987). Neste trabalho, assume-se que as páginas da revista refletem um conjunto de percepções difundidas sobre o ambiente internacional do continente americano e que podem estar vinculadas ao discurso dominante na OEA ou, em outros momentos, configurar ecos de opiniões motivadas por percepções divergentes.

No mesmo caminho, procura-se identificar a influência daquilo que Lars Schoultz chamou de mindset - estrutura mental - e que, segundo o próprio, "determina os contornos básicos da política dos Estados Unidos" (1998. p. V) em relação aos países latino-americanos, apresentando-os como atrasados, inóspitos e dirigidos por homens corruptos, mas principalmente, instáveis e suscetíveis ao avanço de grupos esquerdistas e portanto sujeitos ao monitoramento norteamericano permanente durante a Guerra Fria.

\section{Américas e o Pan-americanismo}

A ideia da existência de uma união entre os povos das Américas, especialmente em sua acepção política, é bastante antiga. Antes mesmo da efetivação da independência política das colônias espanholas na América, Bolívar já propugnava em 1815 - durante o exílio na Jamaica - que desse processo de liberação política deveria resultar a unificação dessas possessões em uma grande nação latino-americana, embasada nos princípios do pensamento liberal: 
nação, com um único vínculo ligando as partes entre si e ao todo. Visto que ele já possui uma só origem, uma só língua, um só corpo de costumes e uma só religião, deveria, consequentemente, ter um só governo que confederasse os vários Estados que serão formados. (Bolívar, 1992)

O primeiro passo no sentido de se formar uma confederação entre os Estados latino-americanos recém libertados aconteceu com a realização do Congresso do Panamá, em 1826, o qual, dadas as condições históricas do momento, não obteve o êxito esperado. (Santos, 2003, p.74-75)

Uma nova tentativa de estabelecimento de uma cooperação multilateral entre os países do continente foi realizada com a convocação de um congresso de jurisconsultos - por iniciativa do governo peruano - entre o final de 1877 e 1878 , com o objetivo de estabelecer normas uniformes para o Direito Internacional Privado. Embora outros países tenham sido convidados, não compareceram ao encontro, de forma que foi estabelecido um acordo pelos delegados da Argentina, Bolívia, Chile, Cuba, Costa Rica, Equador e Peru, abrindo espaço para que um novo congresso fosse convocado por Uruguai e Argentina em 1888, o qual resultou na assinatura de diversos tratados de direito internacional nas áreas cível, penal e comercial pelos mesmos países. (idem, p.76)

A eclosão da Guerra do Pacífico motivou uma nova tentativa de integração, discutida no Congresso Bolivariano de Caracas, em 1883. Embora os EUA tenham se mantido afastado de qualquer movimento integracionista, o Secretário de Estado James Blaine chega a propor a realização de uma conferência entre as nações americanas com "o propósito de considerar e estudar os métodos para prevenção de guerras entre as nações da América [...] e cuidar dos interesses de todos no futuro" (Fenwick, 1965, p.46), entretanto, não encontra apoio político interno para levar o projeto adiante.

A primeira reunião de países do continente só se efetivou em outubro de 1889, após o Congresso norte-americano ter autorizado o presidente a convidar os países da América Central e do Sul para uma conferência em Washington, cujo objetivo era considerar um conjunto amplo de questões que envolviam o problema da segurança continental, e, principalmente, das relações comerciais entre os 
países. Dessa conferência - que entrou para a história como Conferência Internacional Americana - surge a primeira união concreta e formalizada entre os países do continente americano, a União Internacional das Repúblicas Americanas ou União Pan-Americana.

Inspirada pela visão do Secretário James Blaine, a delegação norteamericana à Conferência defendeu medidas que buscavam facilitar o comércio entre os EUA e as outras repúblicas americanas. No entanto, o alcance das propostas criou uma sensação entre as delegações presentes de que se buscava criar um organismo normativo supranacional, capaz de ditar políticas para a região, o que evidentemente não interessava a países que lutaram tão arduamente por suas autonomias. Ao final da Conferência o que se atingiu de concreto foi a constituição de um escritório comercial sediado em Washington, e a adoção de arbitramento obrigatório para resolução de disputas entre os países americanos.

Entre esta primeira Conferência e a $9^{a}$ Conferência das Repúblicas Americanas na qual a OEA foi fundada em 1948, em Bogotá, muitos foram os esforços de criar um espaço de diálogo e de negociação entre os Estados do continente. Acordos visando a ampliação do comércio, a defesa e a segurança do continente deram a tônica das Conferências e das reuniões das diversas comissões criadas, como a Comissão Inter-americana de Jurisconsultos, encarregada de estudar meios de uniformizar das normas jurídicas do Direito Internacional Público e Privado para facilitar as relações - especialmente as comerciais - entre os países da região.

Existem diversas interpretações sobre o significado do pan-americanismo, mas podemos resumir a discussão a duas acepções. Uma, vinculada ao pensamento latino-americano e originada durante os movimentos de independência e outra, vinculada ao pensamento norte-americano consubstanciado na Doutrina Monroe. O pan-americanismo de acepção latino-americana estaria então baseado no ideal de união e solidariedade continental contra a exploração europeia. Por outro lado, o pan-americanismo norte-americano buscaria garantir o afastamento dos países europeus para que o continente permanecesse como sua área de influência exclusiva. 
Os defensores da acepção latino-americana costumam demonstrar uma postura que opõe as "pobres e fracas nações do sul" ao "colosso do norte", numa tentativa de mostrar que as ambições imperiais do segundo teriam servido como meio de opressão dos primeiros.

Tal perspectiva, ainda que revestida de um grau elevado de crítica ao poder hegemônico exercido pelos Estados Unidos na região, parece desconhecer o fato que a relação entre norte-americanos e latino-americanos não é uma via de mão única em que estes aceitam passivamente as determinações impostas pelos primeiros. Embora não seja pretensão deste trabalho esgotar o debate sobre o significado do pan-americanismo seja para os EUA, seja para os países latinoamericanos, é importante esclarecer que mesmo reconhecendo a validade de tal postura, não parece que esta seja a mais adequada ou mesmo a forma mais realista de ver a questão. Não se pode negar que o governo norte-americano tivesse objetivos muito bem definidos ao convocar a I Conferência Internacional Americana, porém, se não houve o convencimento das repúblicas presentes ao encontro, também não Ihes foi possível impor esses objetivos - visto que a formação de uma união aduaneira no continente, principal objetivo a ser atingido, não obteve êxito.

A América Latina não é um todo indiviso, mas um conjunto de nações com tradições e interesses bastante diversificados e, em alguns momentos, divergentes. No período em estudo cada um deles apropriou-se do ideal pan-americano e conferiu a ele os significados que Ihes pareceram mais adequados aos seus interesses e necessidades.

Tão pouco se deve assumir que a noção norte-americana do panamericanismo tenha se constituído em um conceito imutável. Se por um lado os planos de Blaine giravam em torno do estabelecimento da hegemonia econômica dos EUA sobre o continente, a política norte-americana dos anos 1930 e 1940 ganhou muito mais flexibilidade e permeabilidade às reivindicações latinoamericanas, que puderam aproveitar-se da retórica de unidade e cooperação continental para atender a seus próprios interesses, inclusive no sentido de refrear o imperialismo norte-americano. (Streeter, p.167)

Um exemplo dessa mudança no relacionamento dos EUA com a América 
Latina pode ser encontrado na Política da Boa Vizinhança, desenvolvida pelo governo de Franklin D. Roosevelt durante os anos 30 e 40 do século XX. A PBV dá uma nova roupagem à retórica do pan-americanismo, baseando-se numa suposta unidade de origem e de valores como justiça, liberdade e democracia entre as Américas do Norte e do Sul (idem, p.169). Importante lembrar que tal mudança não ocorreu gratuitamente. As pressões do cenário internacional advindas da Depressão e do surgimento de regimes autoritários na Europa; o mal-estar regional para com as frequentes intervenções norte-americanas e a maior complexidade política e social dos países do sul do continente forçaram a revisão da atuação dos EUA perante seus vizinhos.

Neste trabalho o pan-americanismo é tratado como um conceito que serviu de base para a união continental sob a liderança dos EUA. Nas páginas da revista Américas, a união em torno da OEA foi tratada como resultado natural do processo iniciado em 1826 por Bolívar, dando forma orgânica ao ideal pan-americano.

\section{Américas? Que revista é essa?}

Assim como a Organização dos Estados Americanos (OEA) é considerada por seus dirigentes como continuidade da União Pan-americana (UPA), fundada em 1889, Américas também é vista como continuadora da tarefa exercida pelo Boletim da União Pan-americana. Editado entre outubro de 1893 e novembro de 1948, o Boletim cumpria a dupla função de dar publicidade às discussões políticas da UPA e de divulgar aspectos da vida cultural e econômica do continente, entretanto, as dificuldades de financiamento sofridas pela entidade obrigavam a um atendimento apenas parcial desses objetivos, daí a decisão de desmembrar o Boletim em duas publicações distintas, a já citada Américas e os Anais da Organização dos Estados Americanos, esta última, encarregada de publicar os documentos oficiais. Nas palavras do Secretário Geral Alberto Lleras Camargo:

Para o estímulo das relações não oficiais entre os povos, bem como para difundir os aspectos mais interessantes da sua evolução e progresso, tornar mais conhecidas as formas de sua cultura e, sobretudo, para pôr em 
evidência os problemas que se antolham ao seu desenvolvimento atual, com um critério acessível à cultura e aos sentimentos populares, haverá também uma revista mensal editada por enquanto em três idiomas, que cumprirá as finalidades que se propôs o Boletim da União Pan-americana, talvez com o emprego mais intenso de todos os recursos informativos de que dispõe atualmente a União, e com uma apresentação literária e gráfica mais atraente.

Pode-se perceber que além de reforçar a divulgação dos debates sobre o sistema interamericano travados no interior da OEA, também era necessário chegar ao cidadão comum, atingir os "sentimentos populares", para que estes estivessem em consonância com os objetivos do ideal pan-americano.

A revista Américas teve sua publicação iniciada em março de 1949, com o objetivo de servir como um veículo para a promoção do entendimento e da união entre os povos americanos através do conhecimento mútuo, ou nas palavras da própria revista "apresentando a América aos americanos". A redação da revista estava sediada em Washington, sob a supervisão direta do Secretário Geral da OEA, o qual possuía plena convicção sobre a necessidade de um veículo com tais características, conforme vimos na citação de seu relatório. Ainda assim, eram frequentes as divergências entre o Secretário Geral e a Comissão de Finanças, por conta do seu custo elevado de publicação e distribuição. Não será possível entrar em detalhes, mas segundo os relatórios da Comissão de Finanças da OEA, a produção da revista consumiu cerca de $4 \%$ do orçamento total da entidade, em seu primeiro ano, com uma tiragem de 22 mil exemplares. Uma década depois, esse número chegou a 580 mil exemplares.

As dificuldades iniciais para a distribuição da revista derivavam do seu processo editorial, pois entre 1949 e 1954, as edições de Américas eram escritas e impressas em Washington, o que atrasava sua chegada aos destinos programados, mas permitia que o conteúdo de todos os exemplares fosse idêntico, havendo apenas algumas poucas variações destinadas a adequar cada número ao seu público leitor. Esse processo também permitia que o conteúdo da publicação estivesse sempre sob o controle da Secretaria Geral. Tomando como base a edição em Língua Inglesa, a equipe de redação vertia os artigos para o espanhol e o português e selecionava as colaborações específicas para cada edição. O único 
ponto significativo de diferenciação entre as edições era a coluna "Know your neighbors" (Conheça seus vizinhos - escrita com fatos considerados pitorescos sobre a América Latina), existente na edição norte-americana e que na versão em Língua Portuguesa era substituída pela coluna "Curiosidades da Língua Inglesa”.

Ao longo das décadas de 1950 e 1960, houve um crescimento acelerado no número de exemplares de Américas, ampliando seu alcance entre os leitores e tornando-a o principal veículo de propaganda da OEA em todo o continente, chegando a vender 70.000 exemplares somente no Brasil. Embora o risco de uma revolução socialista na América Latina fosse considerado pequeno durante os anos 1950, uma série de iniciativas no campo simbólico estiveram unificadas em torno da luta contra o comunismo, fazendo uso de meios como o cinema e a literatura para veicular o discurso anti-russo. Essas iniciativas eram consideradas parte fundamental da luta, recebendo atenção especial de indivíduos como Louis Hartz, influente cientista político norte-americano e um dos grandes defensores do excepcionalismo do povo dos Estados Unidos. Hartz defende a importância da propaganda para a consecução dos objetivos norte-americanos:

\footnotetext{
Uma vez que a luta corrente contra o comunismo é em grande parte uma competição ideológica por lealdades humanas, ela trouxe à tona a psicologia americana. Uma das questões em jogo é a da mensagem (grifo do autor) social para competir com o apelo do comunismo em várias partes do mundo. Uma vez que o credo americano é uma fé arraigada... obviamente não é uma teoria da qual outras pessoas possam facilmente apropriar-se e entender (Hartz 1994, p. 305).
}

Hartz vê o combate ao comunismo como parte de uma disputa que tem seus limites além da simples competição política e econômica entre sistemas de produção. Para ele, não bastava simplesmente convencer os indivíduos dos malefícios do comunismo, mas era necessário principalmente mostrar-lhes a superioridade da forma norte-americana de concepção do mundo.

Américas era parte ativa nesse empreendimento. A publicação passou a integrar o esforço coletivo e organizado de diversas instituições norte-americanas em produzir informação sobre a América Latina para consumo no mercado norteamericano . Conhecer os povos latino-americanos, seus modos de vida, seus 
costumes, era tarefa para intelectuais, pesquisadores acadêmicos, jornalistas e cientistas, mas também para militares e homens de negócios. Enfim, um amplo espectro de estudiosos voltava seus olhos para o sul do continente objetivando entendê-lo, para dessa forma, melhor controlá-lo. Com o prestígio da cientificidade, tais informações, logo se colocavam acima dos conhecimentos tradicionais, dessa forma, podendo ser consumidas internamente pelo público norte-americano, pelos formuladores da política norte-americana para essa aquela região e, mais importante, poderiam ser reintroduzidas naquele espaço, servindo como base para que os povos latinos desenvolvessem novas percepções sobre si mesmos, orientadas pelo olhar estrangeiro.

A outra face da moeda nesse processo era a difusão desse conhecimento. Nesse aspecto, o desenvolvimento tecnológico jogou um papel importante, permitindo sua distribuição maciça de informações através de jornais, revistas e outros meios audiovisuais como o cinema e o rádio.

Com base nesse arcabouço de informações e conceitos, geravam-se novos discursos sobre a América Latina, entretanto, um fator persistente nessas narrativas é a dicotomia entre a civilização e a barbárie. Nas primeiras décadas do século XIX, o relacionamento EUA e as repúblicas latino-americanas era marcado pela crença de que enquanto que os EUA representavam a liberdade, a democracia, o progresso econômico e a virtude, os povos latinos eram autoritários, antidemocráticos, economicamente atrasados e corruptos, ou seja, representavam o negativo da civilização norte-americana.

O discurso pan-americano trouxe uma nova roupagem ao relacionamento entre os EUA e a América Latina, enfatizando a cooperação entre Estados e abrindo espaço para discursos que procuravam representar as repúblicas do sul como "locais de investimento potencialmente lucrativo para os investidores norteamericanos" (Salvatore, 1998, p. 81). O centro e o sul do continente passaram de lugares sem lei a terras de oportunidades, tanto para negociantes quanto para pesquisadores das mais variadas especialidades, ao mesmo tempo em que permanecia o contraste entre o antigo e o novo, representado na oposição entre as expectativas futuras baseadas na potencialidade dos mercados latino-americanos e 
a contemplação das glórias passadas das civilizações pré-colombianas.

Contudo, não se pode ignorar que por ser um veículo de comunicação produzido por um organismo multilateral no qual a diversidade de países e visões sobre os temas econômicos, sociais e políticos do período eram a tônica, por mais que em Américas predominasse uma visão vinculada à leitura que os representantes norte-americanos na entidade possuíam sobre os problemas da América Latina, nem sempre ela foi veículo exclusivo para difusão do discurso oficial, como se pode observar pela disputa de posições em torno da promoção do desenvolvimento econômico na região, descrita demoradamente em suas páginas a partir da segunda metade dos anos 50 do século passado.

\section{Américas e a Guerra Fria}

As décadas de 1950 e 1960 foram marcadas pela grande incidência do debate sobre temas políticos e econômicos que refletiam a influência exercida pelo conflito bipolar sobre o ambiente regional. Há dois marcos importantes desse período que ajudam a demonstrar a mudança do perfil editorial da revista: a Reunião de Consulta de Ministros de Relações Exteriores realizada em 1951 e a Revolução Cubana, em 1959, por forçar o abandono do perfil de publicação cultural e promover a incorporação de discussões sobre o desenvolvimento econômico e o confronto bipolar.

O final da II Guerra Mundial gerou expectativas na América Latina em relação ao apoio que seria oferecido pelo governo norte-americano para a promoção do desenvolvimento econômico local. Entretanto, da parte dos EUA, a diretriz principal era que os governos locais deveriam abrir suas economias ao investimento privado, o qual viria então a tornar-se a principal fonte de capital para inversão nos países latino-americanos, uma vez que os fundos estatais norte-americanos de então estavam sendo utilizados prioritariamente para financiar a reconstrução da Europa e do Japão, como parte de sua estratégia global de combate à influência soviética (Vizentini. 1995, p. 63-65; Cervo \& Bueno. 2002, p.270).

Além disso, os analistas norte-americanos acreditavam que a América Latina 
havia deixado de desempenhar um papel relevante para os interesses globais do país, portador de maiores responsabilidades em nível internacional, uma vez que "[...] estando sob a liderança incontestável dos Estados Unidos, não foi percebida como uma área de risco ou prioritária do interesse norte-americano, que se dedicou a barrar o avanço soviético em outras localidades" (Pecequilo. 2005, p.217). A mesma autora afirma que o período é marcado por um "crescente distanciamento entre os EUA e seus parceiros latino-americanos" (idem, p.219) que recuaria apenas a partir do final da década de 1950.

Entre 1950 e 1959, Américas absorveu e reproduziu o debate em torno da promoção do desenvolvimento econômico na América Latina, transparecendo claramente a visão norte-americana da questão. Por outro lado, os governos locais também utilizaram o espaço da publicação como meio de pressionar o governo dos EUA e a própria OEA a atender suas reivindicações com as manifestações recorrentes de seus representantes na entidade.

Durante esse período a promoção do desenvolvimento econômico ganhou tamanha relevância para o conjunto dos países latino-americanos que as matérias que destacavam os problemas de infra-estrutura e as obras e projetos que poderiam ajudar a superá-los estavam presentes em todos os números publicados. Ao final da década, com o lançamento da Operação Pan-Americana, proposta pelo presidente Juscelino Kubitschek, e da Aliança para o Progresso, a problemática da melhoria das condições materiais dos povos americanos passou a ser tratada como medida preventiva ao avanço dos movimentos revolucionários na região.

Seguindo a linha de raciocínio desenvolvida pelo Departamento de Estado dos EUA, Américas privilegiou os relatos de empreendedores privados sobre suas experiências de enriquecimento no continente. Em sua maioria eram empresários que encontraram oportunidades econômicas e que procuraram utilizá-las como exemplo para que os povos latino-americanos pudessem eles mesmos desenvolver suas economias, em uma espécie de sistema de auto-ajuda, em contraponto às constantes reivindicações locais por investimentos públicos do governo norteamericano na região. Os projetos de cooperação técnica, de ensino, de treinamento de pessoal técnico para agricultura e pecuária desenvolvidos pela OEA no 
continente eram amplamente divulgados na revista como parte das conquistas do pan-americanismo para a região.

A América Latina era tratada como uma espécie de "ilha de prosperidade", na qual todo empreendedor corajoso poderia obter bons resultados. A importância dada aos investimentos privados era parte componente da retórica do pan-americanismo, sobre como a reprodução de experiências supostamente bem sucedidas nos EUA poderiam beneficiar a região como um todo. A esse respeito, Emily Rosenberg (apud Sheinin, 2000, p. 170) afirma que o componente econômico do pan-americanismo pode ser definido como "liberal desenvolvimentismo" (liberal developmentalism), ao defender a promoção do desenvolvimento das economias latino-americanas com base em investimentos estrangeiros, livre mercado e abertura comercial.

Entretanto, ao se comparar tais afirmações com o registro histórico, pode-se perceber as incongruências existentes o que se propunha como política para a América Latina e a experiência da república do norte. Paul Bairoch, afirma que os EUA "representam a pátria e o bastião do moderno protecionismo", após avaliar os efeitos das políticas tarifárias do século XIX sobre a industrialização do país e conclui que sem essa proteção, "cerca de metade das indústrias têxteis da Nova Inglaterra teriam ido à falência" (apud Sheinin. Idem, p.171).

O ataque da Coréia do Norte ao território sul-coreano em junho de 1951 foi percebido pelos norte-americanos como um ato de agressão ao mundo livre, um movimento soviético em direção à expansão de seu poderio, levando os EUA a tomarem diversas iniciativas como resposta a tal situação, entre as quais, a solicitação junto ao Conselho da OEA para a reunião de seu órgão de consulta, a Reunião dos Ministros de Relações Exteriores, com o objetivo de discutir as implicações da agressividade comunista para a segurança continental:

O comunismo levou os Estados Unidos a adotar um plano de mobilização econômica e a pedir às nações latino-americanas, por meio da Reunião de Consulta, que pusessem também em prática medidas acopladas às diretrizes por eles traçadas. [...] O governo brasileiro sentiu que o momento era o mais adequado para, sustentando sua própria visão sobre mobilização econômica, reclamar a cooperação econômica do parceiro do norte (idem, p. 273-274) 
A documentação relativa à preparação do encontro revela que, na ocasião em que a solicitação norte-americana foi apresentada, as medidas de caráter econômico relacionavam-se especificamente ao esforço defensivo. A nota apresentada pelo representante norte-americano no Conselho da OEA, Paul C. Daniels pedia a reunião, pois:

\begin{abstract}
"A orientação agressiva do Comunismo internacional, levada a efeito por meio de seus satélites, criou uma situação em que se acha ameaçado o mundo livre em sua totalidade. [...] Como o declarou o Presidente Truman, os Estados Unidos, tendo em mira organizar sua força em defesa desses princípios, adotou um programa de emergência destinado aos necessários preparativos econômicos e militares.

Havendo adotado urgente mobilização em prol da defesa comum, os Estados Unidos desejam consultar seus companheiros, os membros da Organização dos Estados Americanos, no tocante à situação mundial que todos enfrentamos, e à coordenação de esforços comuns, necessária nesta conjuntura".
\end{abstract}

Percebe-se claramente que a cooperação econômica com o continente, em um sentido mais geral, não era a preocupação central do governo Truman naquele momento. Seu objetivo central era buscar a cooperação latino-americana em torno do novo esforço de guerra que se avizinhava, chegando a invocar os termos do Tratado Interamericano de Assistência Recíproca para tal finalidade. Contudo, tal ofensiva não foi bem recebida pela representação dos demais países-membros, que voltaram a deixar claro que a sua pauta principal era a superação do subdesenvolvimento econômico.

Já nos primeiros meses de 1952, Américas passou a trazer artigos que procuravam mostrar as grandes oportunidades de investimentos existentes no continente. Uma das mais interessantes foi Bonanza de Ferro, a respeito de uma enorme jazida de minério de ferro encontrada na Venezuela, segundo o autor, "o mais rico depósito de minério de ferro já descoberto neste planeta". O autor faz uma ampla descrição do empreendimento e da importantíssima participação de empresas privadas na exploração da jazida - na verdade tratava-se de apenas uma empresa, a Orinoco Mining Company, subsidiária da US Steel, empresa norte-americana do ramo da produção de aço - e sobre os efeitos benéficos da empreitada:

"A descoberta dessa Bonanza de Ferro na Sexta-Feira Santa de 1947 deu início e continuidade ao crescimento da antes desolada província de Bolívar. 
Ciudad Bolívar, a capital da província, transformou-se de uma pacata cidade portuária de quarenta mil pessoas em um centro industrial e comercial frenético com cerca de sessenta mil."

Ou seja, empreendimentos como a mineração eram apresentados em Américas como anunciadores da chegada do progresso para as regiões atrasadas e "desoladas" dos países do sul do continente. Uma vez que as preocupações para com os efeitos ecológicos da ação humana são bastante recentes, pode-se entender a questão sob o ponto de vista do domínio da humanidade sobre a natureza. $\mathrm{A}$ capacidade de intervir e modificar o meio-ambiente a partir do conhecimento técnicocientífico e em conformidade com as necessidades e desejos do ser humano era vista como uma das grandes virtudes que as sociedades humanas poderiam desenvolver (Prado, 1999, p.179-181). Além disso, esse artigo possuía ao menos dois pontos em comum com muitos outros publicados na revista ao longo do período estudado: primeiro, a representação de determinadas regiões da América Latina como "regiões de fronteira", espaços nos quais as conquistas da civilização ocidental ainda não haviam chegado (Turner, 1976) e segundo, a defesa dos benefícios do investimento de capital privado para o desenvolvimento da região, entendido, naquele momento, como crescimento da atividade econômica.

Suas páginas também passaram a ser frequentemente ocupadas com artigos e notas a respeito das reformas econômicas necessárias para facilitar o afluxo de capital estrangeiro para a América Latina. As mais importantes estavam relacionadas à abertura comercial e à revisão das políticas fiscais em cada nação, mas também estavam presentes informações e notícias sobre os programas de cooperação técnica e sobre as propostas voltadas para o desenvolvimento local das populações, enfatizando o cooperativismo, visto como meio de incentivo à iniciativa privada, em substituição à atuação econômica do governo:

Por um bom tempo o movimento cooperativista foi podado nos países latinoamericanos, quase sempre encorajado ou mesmo dirigido pelos governos nacionais. Apesar das grandes dificuldades, o movimento está se tornando mais importante a cada dia. O Cooperativismo, que é uma das mais engenhosas e efetivas soluções para os problemas econômicos e sociais não é uma religião, nem uma teoria política ou filosófica. Primeiramente, trata-se de uma técnica. [...] Através de sua Seção de Cooperativas, a União Pan-Americana (UPA) vem promovendo, há muitos anos, a troca de 
informações entre os líderes das cooperativas das Américas e, com recursos muito limitados, vem tentando treinar alguns especialistas. Quando a UPA lançou o Programa de Cooperação Técnica da OEA, o Conselho Interamericano Econômico e Social percebeu que os povos americanos se beneficiariam imediatamente se $\mathrm{o}$ trabalho modesto que vinha sendo desempenhado pela UPA nesse campo fosse intensificado.

O papel a ser desempenhado pela OEA ficava claramente estabelecido. O organismo deveria levar conhecimento e orientação para as regiões menos desenvolvidas do continente para que a partir daí fosse possível tirar a região do atraso em que se encontravam.

As dificuldades existentes no comércio entre os países do continente também figuravam entre as preocupações da publicação. George C. Compton, editor associado de Américas que publicou o texto "O que está acontecendo com o comércio do hemisfério?" no qual o autor analisava as mudanças ocorridas no comércio hemisférico e procurava avaliar quais seriam as possíveis consequências da industrialização sul-americana para essa atividade (p. 03).

De início, Compton fazia uma avaliação otimista, mostrando o crescimento e a diversificação das trocas comerciais realizadas pelos países latino-americanos entre si e com os EUA, e indicando como fator positivo o equilíbrio existente no comércio entre América Latina e Estados Unidos em termos quantitativos. A seguir, ao analisar as tentativas de industrialização, afirmava:

\footnotetext{
Um fator significativo que agora afeta as possibilidades comerciais é o crescimento da industrialização em muitos países latino-americanos. Isto significou $O$ incremento da produção mecanizada em áreas subdesenvolvidas - o que, aliás, contribuiu para a escassez de dólares no pós-guerra [...]. Mas, a longo prazo, as vendas de maquinário têxtil, por exemplo, não poderão compensar por si só a perda do mercado para os produtos têxteis.
}

Compton também criticava o otimismo com o qual alguns economistas viam tais iniciativas de industrialização e substituição de importações em setores básicos das economias latino-americanas, pois considerava que as mesmas poderiam ser compensadores para os produtores industriais mais antigos na medida em que as rendas internas latino-americanas subiriam e esses países poderiam adquirir mais 
bens de consumo como televisores e outros ainda não produzidos localmente, entretanto, "seu efeito geral para o comércio dependeria muito do tipo de industrialização realizada e da eficiência produtiva que as novas nações industriais fossem capazes de atingir".

Seu artigo ainda apresentava outras preocupações, relacionadas à obtenção de matérias-primas e à produção de alimentos - ambos fornecidos tradicionalmente pelos países periféricos e, no caso, pela América Latina:

\begin{abstract}
Industrialização significa que mais matérias-primas serão utilizadas, e os lucros resultantes significam que a demanda por alimentos vai crescer. Se a expansão industrial continuar e a produção total atingir os níveis máximos, o suprimento de alimentos e matérias-primas também (deverão chegar ao máximo). De onde eles virão?
\end{abstract}

Vê-se que o centro do raciocínio de Compton não estava exatamente relacionado aos destinos da industrialização nos países latino-americanos, mas sim às consequências que esse processo traria para a indústria e o comércio dos países de industrialização mais antiga, pois se nações como Brasil e Argentina passassem a investir pesadamente no desenvolvimento de sua produção industrial, seria lógico admitir que ambos utilizassem os recursos anteriormente exportados para suprir as próprias necessidades, ocasionando redução da disponibilidade de matérias-primas e alimentos para o comércio exterior, ou seja, os países já industrializados precisariam lidar com uma possível alta dos preços desses artigos e, até mesmo, com a sua escassez.

Matérias como essa não eram casos isolados em Américas. A defesa do comércio internacional e do livre cambismo como instrumentos de desenvolvimento era feita em todos os níveis. Redatores e articulistas retomavam o tema com muita frequência em artigos e na coluna "Na frente econômica", publicada todos os meses, até dezembro de 1969.

A revista também dá muito destaque às operações do Eximbank (Banco de Importação e Exportação), do Banco Mundial, do BIRD (Banco Internacional para a Reconstrução e o Desenvolvimento) e de empresas que tivessem intenção de investir nas Américas do Sul e Central. É possível observar as áreas para as quais 
tais investimentos eram direcionados. Na coluna de novembro de 1953 por exemplo, estão em destaque as linhas de crédito do BM e do Eximbank para atividades agrícolas no Equador e no Panamá; para obras de infra-estrutura na Nicarágua e na Colômbia e para a fabricação de papel no Chile e no Brasil. Também estavam sempre presentes 0 andamento dos programas de cooperação técnica desenvolvidos pela OEA em diversos pontos do continente.

É interessante observar algumas pequenas aberturas que revelavam a situação do comércio no ambiente internacional. Numa dela, a coluna faz um relato detalhado sobre o estado das relações comerciais entre o norte e o sul do hemisfério, demonstrando a "crescente interdependência econômica dos EUA e da América Latina":

\begin{abstract}
Em 1954 provieram da América Latina mais de 32 por cento de todas as importações dos EUA, ou sejam [sic], 44 por cento das exportações latinoamericanas. Além de mantimentos como o açúcar, café e bananas, os EUA precisam também de matérias-primas para abastecer suas indústrias bélicas, matérias essas em número aproximado de trinta, classificadas como "estratégicas", sem falar no petróleo e no minério de ferro. [...] aquelas vinte repúblicas têm economias de exportação, tendo juntas, vendido ao exterior, nestes últimos anos, cerca de 16 por cento de sua produção bruta. [...] Por outro lado, os exportadores norte-americanos têm na América Latina seus maiores fregueses de maquinaria industrial, matérias-primas e mantimentos. De todos os produtos de origem civil exportados pelos EUA em 1954, a América Latina comprou 26 por cento. Uma análise dos diferentes itens demonstra cabalmente a importância desses mercados para a indústria dos EUA. Por exemplo: em 1954, o país vendeu à América Latina 54 por cento dos caminhões e chassis sobressalentes exportados; 43 por cento dos automóveis e chassis; 49 por cento dos preparados farmacêuticos; 30,6 por cento de máquinas para a indústria e 32,2 de máquinas agrícolas; 30 por cento dos têxteis e 44,2 por cento das gorduras, do leite, da carne e outros mantimentos de origem animal.
\end{abstract}

Pode-se notar a delimitação do papel das economias latino-americanas em relação ao mercado norte-americano, ou seja, a tradicional função de fornecedoras de produtos primários permanecia mantida a despeito de todo o discurso em torno do desenvolvimento. Porém, o que consideramos mais relevante é a forma como os países latino-americanos estavam inseridos no contexto internacional mais amplo, ou seja, como fonte de abastecimento para a indústria bélica norte-americana, o que os tornava não apenas comerciantes, mas na medida em que se colocavam ao lado do campo ocidental, os qualificava também como defensores do mundo livre, 
inseridos ainda que colateralmente, na estratégia global dos EUA.

Mais adiante, tratava-se do comércio com o Leste Europeu:

\begin{abstract}
A Rússia manifestou a pouco tempo desejo de intensificar o comércio com a América Latina, e a esse propósito é interessante notar que, à exceção de Cuba (este país vendeu açúcar em considerável quantidade à União Soviética no ano passado), somente a Argentina e o Uruguai têm mantido relações comerciais com a Rússia, tendo aliás recebido menos produtos do que os constantes dos acordos (grifo nosso)
\end{abstract}

O campo socialista era considerado indesejável como parceiro comercial por não cumprir os acordos firmados, deixando patente sua suposta desonestidade.

Partindo do princípio de que a promoção do desenvolvimento na América Latina dependia exclusivamente de investimentos de capital privado, não só articulistas e colaboradores da revista seguiam na sustentação desse argumento. Também empresários e dirigentes latino-americanos eram trazidos de tempos em tempos para manifestar seu apoio a essas ideias nas páginas de Américas. Raúl Nass - venezuelano e redator-assistente da edição em espanhol - entrevistou um grupo de empresários latino-americanos durante a Conferência Interamericana de Investimentos realizada em fevereiro de 1955 em Washington para questioná-los sobre a necessidade de investimentos de capital estrangeiro na região.

De maneira geral, os participantes não rejeitavam a presença do capital estrangeiro em seus países, mas todos manifestaram preocupação com que tais investimentos estivessem vinculados à atividades produtivas e não à especulação. Tal é o caso de José Bosch, empresário cubano, presidente de duas das maiores empresas de capital nacional da ilha - a Bacardi e a TransCuba Oil (empresa recém criada para prospecção de petróleo na ilha) -, de Aldo Franco, brasileiro representante da Confederação Nacional das Indústrias e de Martín Del Corral colombiano, presidente do Banco de Bogotá -, cujo posicionamento resumia a discussão:

Prefiro o capital estrangeiro sempre que, primeiro, procure fomentar novas indústrias, novas fontes de riqueza; segundo, faça sociedade com os cidadãos do país onde se instala; e terceiro, entre no país com o propósito de radicação permanente, e não apenas para realizar lucros fáceis e retirarse. 
A adesão ao chamado "desenvolvimentismo liberal" não era um fenômeno exclusivo dos EUA, também no meio latino-americano havia adeptos. Tal era o caso de Genano Payán - advogado colombiano, representante das empresas norteamericanas Sears Roebuck, Quaker Oats e Procter\&Gamble -, defensor da tese de que não haveria futuro para os países do sul sem a presença do capital privado estrangeiro:

Ficaram demonstradas, mais uma vez, as vantagens que a iniciativa privada trouxe aos Estados Unidos, e a América Latina descobriu o que isso significa. Terminou assim, a etapa motivada pela Segunda Guerra Mundial, em que os latino-americanos viram apenas o lado oficial do poderio econômico dos Estados Unidos, através de empréstimos, ajuda e créditos de Tio Sam. E essa etapa acabou a tempo porque o desenvolvimento da América Latina não espera e só pode receber impulso da iniciativa privada mesmo.

O posicionamento de Payán reproduzia a crença de que apenas o capital privado e a liberdade de iniciativa seriam capazes de reproduzir na região a experiência norte-americana de desenvolvimento econômico, tal como vimos anteriormente com David Sheinin (op.cit.).

Entretanto, mudanças no contexto econômico e político da região começaram a pressionar novamente a estabilidade continental. Segundo Pecequilo (op. cit., p.220), as economias locais não se desenvolviam ao ritmo necessário para atender às demandas internas, o que aprofundou as dificuldades econômicas e sociais já existentes, ajudando a aumentar as críticas ao governo norte-americano por sua falta de atenção para a região, ao mesmo tempo em que os próprios analistas no interior do governo dos EUA começaram a perceber a necessidade de rever suas políticas para a América Latina. O crescimento de grupos políticos de esquerda e a chegada de alguns deles aos governos na região, acendeu a luz vermelha.

A mudança na percepção norte-americana sobre os problemas situados ao sul de suas fronteiras e as demandas vindas dessa região ajudaram a promover uma reorientação - ainda que parcial - nas discussões sobre as formas de financiar o desenvolvimento na América Latina. Disso resultou que a OEA ganhou importância como espaço de discussão sobre os caminhos para a superação do subdesenvolvimento no continente, especialmente a partir de seu Conselho 
Interamericano Econômico e Social (CIES), cuja atuação até 1951 segundo Caldas "havia se concentrado especialmente na questão da assistência técnica" (1995, p.43). Em 1953 o CIES foi reformulado no sentido de estreitar sua colaboração com a CEPAL (Comissão Econômica para a América Latina) da ONU. Em novembro de 1954, ocorreu a Reunião de Ministros da Fazenda durante a Quarta Sessão Extraordinária do Conselho, cujas resoluções revelavam "uma maior preocupação com temas como o desenvolvimento econômico, com a liberalização do comércio entre as Américas e com a questão da cooperação técnica (idem, p.44).

O aprofundamento da questão levou Américas a ampliar ainda mais o espaço para o tema em suas páginas. Além dos artigos da redação e de colaboradores e da coluna fixa (Na Frente Econômica), também os editoriais da revista passaram a ser ocupados por textos que discutiam os problemas econômicos das nações latinoamericanas. O Secretário-Geral da OEA Alberto Lleras Camargo escreveu que:

\begin{abstract}
todos os esforços da OEA só poderão ser considerados bem-sucedidos na medida em que as boas relações que vêm sendo estabelecidas entre os dirigentes políticos também possam ser levadas ao conhecimento de todo o povo do continente. [...] Muito têm sido atingido através do Programa de Cooperação Técnica mantido pela OEA, mas sua efetividade só chegará a um resultado satisfatório quando tais iniciativas forem capazes de produzir benefícios para a melhoria do níveis de vida das populações americanas.
\end{abstract}

Pode-se perceber que as preocupações do Secretário-Geral estavam relacionados a dois aspectos distintos do mesmo problema. $\mathrm{O}$ primeiro deles diz respeito à circulação das informações sobre as iniciativas da entidade, para que o conhecimento sobre suas ações não permanecesse restrito aos grupos de dirigentes e representantes cuja participação direta ou indireta nas discussões o permitisse. Fazer com que "todo o povo do continente" tivesse acesso aos feitos da OEA era parte de seu próprio processo de consolidação política - e Américas era uma dos veículos destacados nessa questão.

O segundo aspecto diz respeito ao efeito prático de tais debates para a vida cotidiana do cidadão comum, ou seja, o sentido das discussões em torno da promoção do desenvolvimento na América Latina estaria, nas palavras do Secretário, na elevação do nível de vida de sua população, no qual também estava 
embutida uma necessidade estratégica, a de reduzir a margem de manobra do comunismo no continente.

Seguindo essa linha de raciocínio, o Embaixador Luis Quintanilha, representante do México no Conselho da OEA, publicou uma das muitas manifestações em prol de um maior envolvimento dos governos nessa tarefa:

\begin{abstract}
A propaganda da OEA é assunto relativamente simples. O que está a exigir sério estudo por parte de todos os governos americanos é o modo de organizar um programa de ação que, independentemente do esforço nacional, contribua para erguer os níveis de vida de todas as nossas pátrias. Há indícios de atividades nesse bom caminho; mas sem uma ideia central, uma estratégia global que se inspirasse no propósito revolucionário de combater a miséria, a enfermidade e a ignorância, a OEA poderá ser vista por muitos como uma entidade cujo traço característico se limite à aquisição de compromissos políticos. Tais compromissos são benéficos porque, graças à solidariedade de nossos Estados, o continente americano fechou as portas ao imperialismo colonial; isso, porém, que no passado foi muito, agora não basta. [...] As vantagens do Sistema Interamericano repousam hoje, principalmente, nas possibilidades que ele ofereça para proporcionarnos meios de melhorar a vida do homem americano (grifo nosso).
\end{abstract}

Pelas razões anteriores, os governos terão de emprestar à cooperação material o mesmo entusiasmo que até agora vêm dedicando à cooperação política (grifo do autor).

Em seu editorial, o representante mexicano expôs claramente as duas grandes preocupações de seu país em relação à OEA: primeiro, a entidade devia fazer-se conhecida em meio à população dos países-membros, não só entre seus governos; segundo, superada a etapa de firmarem-se os compromissos políticos que davam existência política e jurídica ao Sistema Interamericano, era chegada a hora de se estabelecer os compromissos econômicos que auxiliariam na alavancagem das economias latino-americanas, o que envolvia sobretudo o engajamento material do conjunto dos países, conforme o grifo feito pelo próprio autor. Quintanilha ainda vai além:

Quando um camponês, em qualquer canto do hemisfério, houver recebido da OEA algo que lhe permita lutar contra a doença, aperfeiçoar seus cultivos ou abrir os olhos à cultura, e quando esse algo se dever a qualquer atividade do organismo regional, então, e somente então, aquele camponês agradecido saberá que a OEA existe e que, por sua vez, deve apoiá-la. O mesmo pode afirmar-se quanto ao operário que trabalha e luta em nossas cidades. 
Para tornar a entidade conhecida e ganhar apoio das populações pelo continente, era preciso que tais populações recebessem benefícios específicos da entidade, tornando-se assim, menos abertas ao apelo dos grupos de esquerda.

O tom das críticas à política econômica dos EUA para a região aumentou consideravelmente na segunda metade da década, chegando a romper algumas barreiras protocolares, como o editorial escrito por Carlos Dávila, ex-presidente do Chile e então, Secretário-Geral da OEA:

Durante o período de 1946-53 inclusive, o capital líquido exportado dos Estados Unidos para a América Latina, sob todas as formas, particulares e públicas, atingiu 2.400.000.000 de dólares, ou seja, uma média de 300.000 .000 por ano. Durante o mesmo lapso de tempo, os pagamentos latino-americanos aos Estados Unidos, em virtude de dividendos, amortização de dívidas, etc., chegaram a 3.900.000.000 de dólares. Assim, se levarmos em conta a balança de pagamentos relativa à inversão de capitais, o resultado líquido é que os Estados Unidos receberam da América Latina nos últimos oito anos 1.500.000.000 a mais do que lhe enviaram.

[...] Na soma total de inversões na América Latina, o capital norte-americano representa uma cifra insignificante: 9,7 por cento. Dessa soma, a quinta parte procede de fundos públicos. O resto são inversões privadas. Todo restante dos 4.427.000.000 de dólares que se invertem anualmente na América Latina (isto é, quase 90 por cento) é capital latino-americano, economias latino-americanas [...]

Quando se pensa no progresso alcançado pelos países latino-americanos, quase com seus próprios recursos, pode-se bem imaginar quanto não realizariam no futuro se aumentasse o volume de inversões norteamericanas.

O Secretário Geral Carlos Dávila - cujo mandato foi interrompido precocemente - expressava sem nenhum prurido diplomático o descontentamento continental com alguns dos principais problemas nas relações comerciais entre EUA e América Latina: o desequilíbrio da balança de pagamentos devido aos juros e à defasagem nos preços dos produtos primários e o baixo volume de investimentos de capitais norte-americanos na região. Também repercutia a preocupação de muitos governos latino-americanos de promover efetivamente a melhoria das condições de vida das populações locais como instrumento de manutenção da paz e da segurança regionais.

A resposta norte-americana veio durante a Reunião dos Presidentes das 
Repúblicas Americanas, ocorrida no Panamá em julho de 1956. Durante o evento, o então presidente dos EUA, Dwight Eisenhower, profere um discurso no qual exorta as nações do continente a um novo compromisso: "Não podemos agora contar com uma nova fase nesta associação, uma fase em que se apliquem ao bem-estar do indivíduo os mesmos nobres esforços que até agora protegeram e fortificaram a vida coletiva de nossos países?"

Ao propor a formação de um grupo consultivo encarregado de discutir e propor medidas concretas e planos de ação contra a pobreza no continente, Eisenhower não estava pensando em implementar nenhum projeto amplo de investimentos na América Latina, embora fosse favorável à promoção do "desenvolvimento econômico politicamente ordenado na região" como apoio para combater "a ameaça comunista ou outras categorias de subversão anti-americana." (Smith, op.cit. p.127), mas procurava demonstrar aos demais países-membros que sua administração tinha uma postura diferente daquela mantida por seu antecessor em relação a suas reivindicações econômicas, concordando com a realização de uma conferência para discutir especificamente as questões econômicas e comerciais no hemisfério no ano seguinte.

Entretanto, Eisenhower ainda precisava lidar com a oposição doméstica a qualquer tentativa ampliação dos investimentos oficiais dos EUA na América Latina. Vale ressaltar que além das diferenças de avaliação sobre as regiões e atividades que deveriam receber o maior volume de investimentos estatais norte-americanos, havia também no país muito questionamento sobre a eficácia de investir no desenvolvimento econômico da América Latina (Shoultz, op. Cit. p.381).

Frente a essa situação, a Conferência Econômica de Buenos Aires manteve o impasse entre duas posições antagônicas: a dos representantes latino-americanos que defendiam a criação de um banco de fomento com capital inicial de US\$200 milhões pagos em cotas proporcionais pelos países-membros e proposta da criação de um mercado comum, apresentada pela delegação dos EUA.

Apreensivo com o crescimento do antiamericanismo na América Latina e pressionado pelas crescentes reivindicações dos estados centro e sul-americanos, o Presidente Eisenhower decidiu enviar uma comitiva para região com o objetivo de 
levantar informações sobre a real situação do sul do continente e melhorar as relações destes com os EUA, prevenindo uma possível aproximação dos mesmos com o campo socialista (Moniz Bandeira, 1993, p.122-123).

Em maio de 1958, o Vice-Presidente Richard Nixon promoveu uma viagem por diversos países latino-americanos como parte de um projeto de reaproximar as nações do continente. Como já havia feito uma viagem três anos antes pela América Central, sua assessoria decidiu elaborar um roteiro que percorria oito países da América do Sul. Sua passagem por Montevidéu, Buenos Aires, Rio de Janeiro e Lima deu-se sem maiores incidentes - embora tenha havido protestos organizados por estudantes nas duas últimas cidades - porém, ao chegar à Venezuela, Nixon se deparou com uma multidão de manifestantes que o receberam muito agressivamente, chegando mesmo a colocar sua vida em risco. Segundo Schoultz, "durante catorze minutos de agonia, Nixon e sua esposa ficaram presos cada um em sua limusine enquanto a imprensa registrou uma ocorrência única na história dos EUA - manifestantes enraivecidos cuspindo no vice-presidente dos Estados Unidos" (op.cit., p.389).

Meses depois o assunto retornou à pauta graças a um estudo do Rockfeller Brothers Fund sobre os problemas econômicos do hemisfério, no qual se apontava a necessidade de fortalecer as economias do mundo livre "dando sentido construtivo às reivindicações sociais, para que se processem nos moldes da democracia". Entre as muitas recomendações do estudo, estava a da criação de um banco de fomento. $\mathrm{Na}$ edição de novembro, Américas publica a seguinte nota:

Mudança de Atitude

Os partidários da criação de um banco interamericano para financiar projetos de desenvolvimento econômico neste hemisfério tiveram a agradável surpresa de ver C. Douglas Dillon, Subsecretário de Estado para Assuntos Econômicos, anunciar, perante o Conselho Interamericano Econômico e Social, a nova atitude do governo norte-americano com respeito à proposta apresentada em várias reuniões econômicas anteriores. Até então, o ponto de vista dos Estados Unidos fora que as organizações já existentes, como o Banco Internacional e o Banco de Importação e Exportação, poderiam encarregar-se do financiamento necessário.

Mencionando as recentes visitas à América Latina do Vice-Presidente Nixon, do Secretário do Tesouro, Anderson, do Dr. Milton Eisenhower e do Secretário de Estado Dulles, declarou: Em conseqüência dos relatórios 
desses representantes oficiais e dos nossos estudos coordenados dos problemas econômicos do hemisfério, fui autorizado a informar que o governo dos Estados Unidos está disposto a considerar o estabelecimento de uma Instituição Interamericana de Desenvolvimento Regional, com apoio de todos os países membros. (grifo nosso)

Estava dado o sinal verde para o lançamento da Operação Pan-Americana e para a criação do Banco Interamericano de Desenvolvimento. A nota dá ao leitor a nítida impressão de que a dita "mudança de atitude" em relação à criação de um banco para fomentar o desenvolvimento econômico na América Latina teria acontecido de maneira inesperada para os defensores da ideia (no caso, os dirigentes latino-americanos). Como se, além da proposta ter sido apresentada "em várias reuniões econômicas anteriores", nenhum outro tipo de pressão tivesse existido. Tão pouco são consideradas a importância das mudanças conjunturais e das manifestações contra Nixon.

Outra afirmação que chama a atenção é a que atribui a revisão do posicionamento norte-americano aos relatórios de "representantes oficiais e de estudos coordenados" do próprio país, deixando a dúvida sobre a confiabilidade dos dados sobre os problemas econômicos do continente apresentados por instituições como o CIES e a CEPAL, como se para chegar à decisão sobre tal mudança, fosse necessário "ver para crer".

O que os analistas da instituição propunham como medidas que visavam a manutenção da estabilidade era exatamente o que os dirigentes latino-americanos já reivindicavam, mas o ponto a ser ressaltado aqui é que tal construção não tem papel relevante junto ao leitor latino-americano, ao contrário, trata-se de um discurso claramente produzido para consumo do "público interno" ou seja, mais uma vez Américas foi utilizada como um instrumento para o convencimento do leitor norteamericano por meio da criação de uma percepção considerada adequada ao discurso político predominante.

Uma mudança de atitude havia ocorrido de fato, mas não sem um custo. A hesitação de Eisenhower permitiu que a agitação no continente chegasse a níveis que os analistas norte-americanos consideravam perigosos. 
Em 1959, o grupo de revolucionários liderados por Fidel Castro chega ao poder em Cuba. Recebida inicialmente com entusiasmo por alguns e com cautela pelo governo norte-americano, logo passou ser identificado como integrante da ameaça comunista internacional (Shoultz. p.392). A transição no governo não foi noticiada em Américas - como de costume, a revista não tratava das questões propriamente políticas da região - porém, é possível ver que paulatinamente, a Revolução Cubana ganhou um espaço cada vez maior nas páginas da revista, reflexo do crescente aumento das tensões do sistema interamericano.

Entre abril e julho de 1959, Américas reproduziu denúncias dos governos da República Dominicana, Panamá, Costa Rica e Honduras que acusavam o governo cubano de apoiar rebeliões que pretendiam derrubar os governos locais. Com o crescimento das tensões, A OEA decidiu convocar a $\vee$ Reunião de Consulta em agosto do mesmo ano. A pauta da $\mathrm{V}$ Reunião de Consulta versou sobre quatro temas: a tensão internacional na área do Mar das Antilhas; os meios de assegurar a observância dos princípios da não-intervenção e não-agressão; o exercício efetivo da democracia representativa e o respeito aos direitos humanos. De fato, os debates giraram em torno de um único tema, os efeitos da Revolução Cubana para a estabilidade do sistema.

Nesse sentido, se já existia todo um clima de cobrança sobre o governo dos Estados Unidos, também é possível afirmar que a mudança revolucionária em Cuba foi o fator decisivo para o desencadeamento da maior iniciativa de apoio às economias latino-americanas já proposta pelos Estados Unidos, a Aliança Para o Progresso (Smith. p.149).

Ao tomar posse em 20 de janeiro de 1961 como presidente dos Estados Unidos da América, John Fitzgerald Kennedy, afirmou que faria um "vasto esforço cooperativo, sem paralelo em magnitude e nobreza de propósitos, para satisfazer as necessidades básicas do povo latino-americano por teto, trabalho e terra, saúde e escolas". Estava lançada a Aliança para o Progresso (AP), cujo objetivo era investir, ao longo de 10 anos, um montante de mais de 20 bilhões de dólares nas economias latino-americanas, passando a ser considerado por alguns como uma espécie de Plano Marshall para a América Latina. 
A AP não trazia um conteúdo propriamente novo - a rigor, a proposta incorporou aquilo que era um dos cernes das reivindicações latino-americanas, a elevação do volume de investimentos diretos do governo norte-americano - mas inovava ao abarcar setores da economia que até então haviam ficado fora dos projetos de promoção do desenvolvimento, como as estruturas fundiária e fiscal. Também incorporava o combate à pobreza e à desigualdade social, devido ao seu potencial desestabilizador (Rabe. 1999, p.178-180).

Assim como sua antecessora - a Operação Pan-Americana, a AP tinha como princípio geral promover a modernização do capitalismo latino-americano, realizando a "transformação, onde for necessária, das estruturas e dos injustos sistemas de posse e exploração da terra". Pretendia também "assegurar aos trabalhadores justa remuneração e adequadas condições de trabalho", propostas que em conjunto com os programas de habitação, saúde e educação abrangeriam as necessidades básicas das populações latino-americanas.

Entretanto, a principal diferença entre a AP e os projetos que a antecederam era o seu caráter de compromisso político. A "Carta de Punta Del Este" e a "Declaração aos Povos da América", diferentemente da Ata de Bogotá e outros documentos anteriores é explícita ao vincular a aliança política e a ajuda econômica, estabelecendo critérios de cunho político como pressupostos para a concessão da ajuda material. Já em seu preâmbulo, o documento estabeleceu um recorte que divide claramente o sistema interamericano do restante dos atores e sistemas políticos mundiais. A Aliança pressupunha um firme compromisso para com a democracia, tal como compreendida pelo pensamento ocidental:

Funda-se esta Aliança no princípio de que a liberdade e as instituições da democracia representativa asseguram as melhores condições para satisfazer, entre outros, os anelos de trabalho, teto e terra, escola e saúde. Não há nem pode haver sistema que garanta verdadeiro progresso se não proporcionar oportunidade para a afirmação da dignidade do indivíduo, fundamento de nossa civilização.

Consequentemente, no gozo de sua soberania, os países signatários se comprometem, nos próximos anos, a: Aperfeiçoar e fortalecer as instituições democráticas, em aplicação do princípio de autodeterminação dos povos. 
A AP era mais uma das alianças do chamado mundo livre. Com ela, procuravase estabelecer claramente as vantagens do capitalismo liberal e da democracia representativa sobre o sistema socialista, acusado de transformar o indivíduo em escravo do estado e de recusar toda e qualquer liberdade ao cidadão.

Havia uma preocupação de parte dos estados-membros - em especial aqueles de economia mais diversificada - em reforçar o caráter multilateral da AP privilegiando o CIES como espaço de negociação entre os países latino-americanos e os EUA, com uma maior coordenação e orientação regional para os programas. Foi a maneira encontrada pelos dirigentes latino-americanos para driblar a rigidez do controle exercido pela AID (Agência para o Desenvolvimento Internacional). A AID funcionava como elo entre o comitê multilateral da OEA e o Departamento de Estado, no qual o Secretário de Estado Assistente Thomas Mann era o responsável pelos assuntos interamericanos, inclusive a Aliança para o Progresso (Rabe, op.cit. 189). Celso Furtado, representante brasileiro no CIES declarou durante uma das reuniões do Conselho que "cada país é responsável pelo seu desenvolvimento. Cooperação internacional não pode ensinar uma nação como realizar reformas estruturais".

Ao longo de todo o período estudado, o processo de implantação da AP foi amplamente noticiado e debatido em Américas, inclusive com grande destaque para as dificuldades enfrentadas na elaboração e na implementação dos projetos de reformas econômicas, até 1968, quando o tema foi tratado na revista pela última vez por conta da redução dos fundos destinados ao programa. O artigo reproduzia a apresentação feita pelo Secretário Geral Galo Plaza no Clube Nacional de Imprensa dos EUA, em Washington. Segundo ele, a incapacidade de realizar os objetivos da Aliança foi resultado do excessivo otimismo das metas traçadas em sua fase inicial; com a insuficiência da ajuda externa; com o reacionarismo de alguns setores das elites latino-americanas e, finalmente, com a incompreensão dos próprios latinoamericanos sobre o significado da Aliança para o Progresso.

Essa deficiência seria responsável por difundir uma opinião de que AP seria simplesmente mais um instrumento da política externa dos EUA para exercer sua dominação sobre os povos do sul. O autor também lamenta a postura norte- 
americana de reduzir os recursos para a AP, mencionando que isto pode significar a diminuição geral do interesse dos EUA pela América Latina, o que acabaria por se tornar mais um elemento para reforçar o descontentamento da população e o antiamericanismo, aprofundando as instabilidades locais.

A questão de fundo relacionada às dificuldades de coordenação entre a AID e o CIES foi o aprofundamento do confronto político entre os EUA e Cuba no ambiente regional. Após a Crise dos Mísseis, a tensão entre os dois países tornou-se insustentável e a representação norte-americana na OEA inicia o processo de isolamento do regime cubano, que acaba por levar à sua exclusão da entidade em janeiro de 1962, por decisão da VIII Reunião de Consulta dos Ministros de Relações Exteriores.

O encontro foi iniciado com a apresentação do relatório da Comissão Interamericana de Paz no qual o governo da ilha foi mais uma vez acusado de violação sistemática dos direitos humanos e de atuar para promover a subversão no continente.

\begin{abstract}
O objetivo dessa ofensiva é a destruição das instituições democráticas e o estabelecimento de ditaduras totalitárias a serviço de poderes extracontinentais. Os fatos notáveis da intensificação dessa ofensiva são as declarações existentes em documentos oficiais dos corpos dirigentes do movimento comunista internacional, de que um de seus principais objetivos é o estabelecimento de regimes comunistas nos países subdesenvolvidos e na América Latina; e a existência de um governo que é publicamente alinhado com a doutrina e a política exterior dos poderes comunistas.
\end{abstract}

Partia-se do pressuposto de que havia uma ofensiva comunista em curso no continente - bem como no mundo inteiro - e que o governo cubano ao assumir o caráter socialista da revolução passara a fazer parte dela, como um estado teleguiado da URSS.

Além de proibir a participação cubana na OEA, a VIII Reunião de Consulta também criou uma comissão consultiva para auxiliar o Conselho da entidade na elaboração de medidas para conter a expansão do comunismo no continente, a partir de estudos elaborados sobre a suposta atuação de forças sino-soviéticas nas várias repúblicas da região. Américas publicou passagens desses relatórios em quase todas as suas edições ao longo dos anos de 1962 e 1968, na esteira da Crise 
dos Mísseis e seus desdobramentos posteriores.

Em 1967, durante a XII Reunião de Consulta de Ministros de Relações Exteriores, foram discutidas diversas formas de enfrentamento da insurgência que crescia no continente e que era entendida como reflexo da agitação comunista. Ao assumir a presidência da sessão inicial em junho, o embaixador panamenho Ritter Aislán afirmou:

Chega a ser tarefa ociosa, desanimadora e contrária à razão pretender que possa haver progresso econômico na América Latina sem enfrentar-se o problema da subversão de que sofrem os nossos povos.

Tal afirmação ajuda a entender mais claramente a razão das resoluções da XII Reunião de Consulta darem tanto destaque às ações de contra-insurgência e à coordenação sub-regional do combate às guerrilhas. A era do combate à subversão com desenvolvimento econômico havia terminado.

Também chegava ao fim a era da presença da política continental em Américas. Em julho de 1968, o ex-presidente equatoriano Galo Plaza assume como novo Secretário Geral da OEA e começa a pôr em prática parte do plano de reformas que vinha sendo discutido desde a II Conferência Interamericana Extraordinária, realizada em novembro de 1965, na cidade do Rio de Janeiro.

A revista, até então publicada pelo Departamento de Informação Pública, vinculado diretamente à Secretaria Geral da entidade, ficou a cargo da recém criada Divisão de Relações Culturais, vinculada ao também novo Departamento de Assuntos Culturais. Em junho de 1968 a coluna A OEA Em Ação foi publicada pela última vez, informando sobre a suposta conivência do governo do Chile para com um grupo de guerrilheiros que atuavam na Bolívia. No mês seguinte ocorreu a estreia de Hemisfério, seção que passaria a trazer informações sobre assuntos de interesse geral da OEA e acerca de acontecimentos culturais dos países membros. A partir de então, não seriam mais abordados temas de caráter econômico, social ou político, com exceção da Aliança para o Progresso, que ainda ocuparia as páginas de Américas até a edição de dezembro daquele ano, marcando o retorno da revista ao formato adotado inicialmente quando do seu lançamento, voltando a ser uma 
publicação de variedades sobre as Américas.

\section{Considerações finais}

Neste trabalho, procurou-se demonstrar como uma das publicações da OEA, a revista Américas, foi utilizada para construir uma imagem sobre o sistema interamericano para seus leitores.

Ao longo do estudo das duas décadas iniciais do periódico foram abordadas as características que o definiam, seus temas e sua posição relativa no mercado editorial para que fosse possível observar o alcance da publicação entre o público.

O foco de análise esteve voltado sobretudo para apontar as continuidades e rupturas havidas na revista ao longo do período estudado, como forma de verificar de que maneira as mudanças do contexto político do continente se refletiam nesta.

Américas não foi um veículo para discussão do pan-americanismo. Nela, o ideal pan-americano já estava consolidado como um projeto de união do continente americano em torno de ideais universais de justiça, liberdade e democracia. A revista estava pautada por um suposto consenso em torno desses princípios e não havia espaço para manifestação de divergências a esse respeito. $O$ sistema interamericano consubstanciado na OEA e no TIAR era então, uma conquista obtida após mais de um século de vida independente das repúblicas americanas.

Em Américas, o continente era o lugar da prosperidade e da paz, onde o diálogo e a cooperação haviam superado as antigas disputas que tinham levado a velha Europa a mais uma guerra que acabara por tomar proporções mundiais.

De início, os temas políticos e econômicos estiveram fora das páginas da revista, que se manteve como um instrumento de divulgação cultural, mostrando a variedade das manifestações artísticas e os eventos históricos mais marcantes de cada um dos países da região. Esse perfil sofreu modificações graduais ao longo dos anos 1950, incorporando o debate sobre o desenvolvimento econômico que ganhara relevo após o fim da II Guerra Mundial e progressivamente ocupou o centro das preocupações latino-americanas.

A leitura de Américas permite observar o crescimento da preocupação dos países do sul para com o desempenho cada vez pior de suas economias. Permite 
também que se acompanhe o tom cada vez mais elevado da pressão das nações pobres sobre o vizinho rico do norte. Embora não rejeitassem totalmente os investimentos de capital estrangeiro privado, os dirigentes sulistas reivindicavam mais investimento de capitais de fundos públicos com prazos maiores para pagamento e juros reduzidos com os quais poderiam ampliar e/ou desenvolver aqueles setores da economia considerados menos lucrativos ou com retorno de mais longo prazo e, portanto, menos atraentes para os investidores privados, mas ao mesmo tempo, de importância fundamental para essas nações.

O ambiente político e social conflituoso não é claramente percebido em suas páginas, pois as matérias publicadas o deixam deliberadamente de fora. Mesmo os editoriais e os artigos escritos por alguns de seus mais eminentes colaboradores passam ao largo dos problemas e agitações sociais do período. Somente no final dos anos 50, quando a situação atinge um patamar considerado crítico, uma nova modificação do perfil da revista é efetuada.

De 1959 a 1968 Américas assumiu o papel de defensora do modo de vida ocidental, baseado em princípios cristãos e na valorização do indivíduo contra o comunismo ateu, que pretendia transformar o homem em escravo do Estado. Se até então a expansão do comunismo era apenas um risco que o sistema interamericano precisava manter afastado, agora ele tinha assumido forma material no novo governo cubano.

Américas deu uma importante contribuição para a construção da ideia do "perigo vermelho". Cuba foi alvo frequente de acusações de intervenção por parte de diversos países americanos que a consideravam como um instrumento voluntário à disposição do chamado bloco sino-soviético. Segundo a visão propagada na publicação, o governo cubano não passava de um mero preposto por meio do qual a URSS poderia interferir nos assuntos do continente americano. Está claro que as divergências existentes no interior do bloco socialista não eram levadas em conta, bem como o próprio fato de o governo cubano não ter sido declarado socialista até dezembro de 1961.

O destaque dado à Revolução Cubana só rivaliza com o espaço que teve a Aliança para o Progresso. Importante destacar que as duas campanhas (a pró- 
Aliança e a contra-Cuba) foram desenvolvidas paralelamente, num momento em que a promoção do desenvolvimento econômico havia ganho importância estratégica para prevenir insurreições.

A Aliança era mostrada como a melhor forma de impedir que os comunistas e sua propaganda pudessem convencer os povos latino-americanos a voltar-se contra seus governos. Os avanços do programa eram mostrados com entusiasmo, ressaltando-se sempre que a partir de então, a unidade continental em torno dos ideais políticos do pan-americanismo havia finalmente chegado ao patamar econômico e, portanto, à vida do cidadão comum, para a qual a Aliança levaria a tão almejada prosperidade no presente, tornando inúteis as promessas dos comunistas de bem-estar num futuro distante.

Apesar de sua postura abertamente anti-comunista, consideramos que Américas não foi um instrumento exclusivo da política norte-americana. É preciso distinguir duas esferas na publicação, a dos editoriais, que reproduzia invariavelmente o posicionamento de Washington e a das colaborações.

Ainda que os posicionamentos explicitados nela estivessem muito próximos e, em muitos momentos, até identificados com a orientação daquele país, é inegável que houve espaço para a manifestação de posições antagônicas, em especial no que diz respeito à economia continental. A esse respeito, os artigos de grande parte dos colaboradores latino-americanos mostraram muito claramente a diferença entre a sua própria postura e a do governo dos Estados Unidos. Mesmo em questões políticas, nas quais havia menor margem de manobra, a presença de posicionamentos divergentes em dois momentos decisivos - a IX e a XII Reuniões de Consulta - mostram ao analista que existe muito mais a ser visto no sistema interamericano para além do que as coloridas páginas de Américas revelam. Apesar da assimetria nas relações entre os EUA e Estados latino-americanos, é um erro assumir que tal assimetria seja sempre traduzida como submissão.

\section{Bibliografia}

AYERBE, Luiz F. Estados Unidos e América Latina, a Construção da Hegemonia. São Paulo: UNESP, 2002. 
BERGER, Mark T. Under Northern eyes. Latin American Studies and U.S hegemony in the Americas 1898-1990. Bloomington: Indiana University Press, 1995.

BOLÍVAR, Simón. Carta da Jamaica, Escritos Políticos. Campinas: Ed. Unicamp, 1992.

CALDAS, Ricardo W. A Política Externa do Governo Kubitschek. Brasília: Thesaurus, 1995.

CERVO, Amado \& BUENO, Clodoaldo. História da Política Exterior do Brasil. São Paulo: Ática, 2002.

\& RAPOPORT, M. (orgs.), El Cono Sur. Buenos Aires: Fondo de Cultura Economica, 2001.

CHARTIER, Roger. A história cultural: entre práticas e representações. Rio de Janeiro: Bertrand Brasil, 1988.

COX, M. \& STOKES, D. U.S. Foreign Policy. London: Oxford University Press, 2008.

FENWICK, Charles. G. Organização dos Estados Americanos: O Sistema Regional, Rio de Janeiro: GRD, 1965.

GLINKIN, Anatoli. N. El latinoamericanismo contra el panamericanismo: desde Simón Bolívar hasta nuestros días, Moscou: Editorial Progreso, 1984.

GENRO FILHO, Adelmo. O segredo da pirâmide - para uma teoria marxista do jornalismo. Porto Alegre: Tchê, 1987.

GOFF, Jacques Le. A História Nova. São Paulo: Martins Fontes, 2004.

HARRISON, Lawrence E. The Pan-American Dream. Boulder: Westview Press, 1997.

HARTZ, Louis. La Tradicion Liberal en los Estados Unidos: Una Interpretación del Pensamiento Político Estadunidense desde la Guerra de Independencia. México D.F.: Fondo de Cultura Economica, 1994.

JERVIS, Robert. Perception and Misperception in International Politics. New Jersey: Princeton University Press, 1976.

MONIZ BANDEIRA, Luiz A. Presença dos Estados Unidos no Brasil, $2^{a}$ Ed., Rio de Janeiro: Civilização Brasileira, 1978.

PECEQUILO, Cristina. S. A Política Externa dos Estados Unidos. Porto Alegre: UFRGS Editora, 2005, $2^{\mathrm{a}}$ Ed.

PRADO, Maria Lígia C., América Latina no Século XIX: Tramas, Telas e Textos. Bauru: Edusc/Edusp, 1999.

RABE, Stephen G., The most dangerous area in the world: John F. Kennedy confronts communist revolution in Latin America. Chapel Hill and London: University of North Carolina Press, 1999.

SALVATORE, Ricardo D. The enterprise of knowledge. In: Close Encounters of Empire. Writing the cultural history of U.S-Latin American Relations. Durham: Duke University Press, 1998, p. 69-104

SCHOULTZ, Lars., Estados Unidos Poder e Submissão. Bauru e São Paulo: EDUSC/EDUSP, 1999.

SHEININ, David., Beyond the Ideal: Pan Americanism in Inter-American Affairs. Connecticut: Praeger Publishers, 2000.

STREETER, Stephen M. The Myth of Pan Americanism: U.S. Policy toward Latin America during the Cold War, 1954-1963. In: Beyond the Ideal: Pan Americanism in Inter-American Affairs, Connecticut. Praeger, 2000, p.169-182. 
SMITH, Peter. H., Talons of the eagle: Dynamics of U.S.-Latin American relations. New York: Oxford University Press, 2000.

TURNER, Frederich J. The Frontier in American History. New York: Robert E. Krieger Publishing Company, 1976.

VIZENTINI, Paulo. G. F. Relações Internacionais e Desenvolvimento. Petrópolis: Editora Vozes, 1995. 